\title{
On the Interrelation between Cognitive and Emotional Minds in Speech
}

\author{
Shushanik Paronyan, Anna Rostomyan \\ Yerevan State University
}

$\mathrm{R}$ ecent research work carried out within the frames of Discourse Analysis and Cognitive Linguistics comes to prove the essential importance of mental activities in linguistic behaviour. Communication is treated as a process which is largely based on the mental world of the speakers and embraces a great deal of conscious and subconscious framework. Discourse analysts hold that the mental, social and physical realities "get 'activated' by the utterer and the interpreter in their respective choice-making practices, and that is how they become part of language use as elements with which the making of choices is interadaptable" (Verschueren 1999:88).

The aim of the present paper is to focus on some special properties of the mental world which are put to work in the process of communication and to reveal the interplay of the cognitive and emotional aspects of verbal communication.

Admittedly, a great deal of research work devoted to the analysis of the mental apparatus of linguistic behaviour has been carried out in Cognitive Linguistics so far (Sanders 2005; Heritage 2005; Kasevich 1989; Paronyan 2009). As a result, speech came to be regarded as a rule-governed process of social behaviour which is based on certain knowledge structures stored in the cognitive mind. Hence, cognition should be treated as inner mental knowledge which appears on the surface level of the cognitive mind through verbal behaviour. Similarly, mental knowledge is verbalized when it reaches the highest, that is, surface level of the cognitive mind. While the importance of the conscious and subconscious control of the cognitive mind in the process of production and interpretation of linguistic signs has become unquestionable, the involvement of the emotional mind in communicative matters still remains open.

As a matter of fact, the exceptional importance of emotions in human life has already been stated both in linguistics and in some social sciences (pragmalinguistics, neurolinguistics, psycholinguistics, cognitive linguistics, social psychology, cognitive psychology, sociology). The analyses of verbal behaviour which proceeds in the form of negative emotional colouring and results in conflict talk illustrate the major role of the emotional mind (the speakers' emotions, beliefs, desires and wishes, motivations and intentions) in shaping the communicative context. No doubt, the involvement of the negative emotional attitude of the interlocutors in the process of communication becomes obvious in terms of production and interpretation of speech. Hence, ruled by certain negative emotions, speakers use language units (words, phrases, structures, speech acts) carrying negative implications and, in doing so, they get involved in contradictory types of interaction (conflict talk, quarrel, argumentation, row, etc.) (Paronyan, Bekaryan 2007). Obviously, the positive/negative emotional attitude of the speaker towards the parameters of the linguistic situation is related to his/her evaluative competence and, therefore, has cognitive significance. Thus, we assume that the analysis of the linguistic mechanisms of verbal- 
ization of emotions, which has become quite actual today, should be carried out on the basis of cognitive evaluation of emotivity.

It should be stated that emotivity is often related to the affective behaviour of the speakers. Emotions are defined as strong feelings which constitute the part of the person's character (Oxford Advanced Learner's Dictionary 1997). Naturally, if we want to bring to light the innate nature of the emotive mind, we should penetrate into the inner mental world of the speaker and examine how this or that emotion is articulated in speech. No doubt the linguistic analysis of emotiveness cannot be carried out without any resort to cognitive science - Cognitive Psychology, Cognitive Linguistics.

The analysis of emotions from the psychological perspective raises the question of the relationship between emotive experience and bodily expression, that is, perception and expression of emotions. In this connection two contradictory points of view can be stated. According to the traditional theory, emotions are feelings or at least experiences of a special type which involve feelings. Hence, when faced with an external stimulus, human beings first of all experience emotions, their reaction to the external situation comes next, that is, response follows emotion. The proponents of this theory make it clear that emotions should be regarded as mere sensations which are evoked from any perceived external stimuli and are completely devoid of any cognitive elements (Murray 1964).

Contrary to this, another point of view, which acknowledges the cognitive element in emotions, was put forward by a group of psychologists (W. James, C. Lange, W. Cannon, $\mathrm{Ph}$. Bard, et al.). According to the so-called James-Lange theory, a person's immediate psychological response to the outward situation precedes his experience of a particular emotion. In his work "The Principles of Psychology", W. James stated that "the bodily changes follow directly the perception of the existing fact, and that our feeling of the same changes as they occur is the emotion" (James 1890:449). Apparently, according to the so-called James-Lange theory, conscious experience follows the bodily reactions which are more or less automatic reactions to stimuli in the environment: we feel afraid because we shiver, we feel sorry, disappointed and sad, because we cry, we feel happy because we smile and not vice versa.

Trying to give a comprehensive solution to the problem of the relationship between emotional experience and bodily expression, some psychologists came to treat emotion as a process and focused mainly on its final part, i.e. expression, ignoring its initial stage perception. An alternative interpretation of emotions was proposed by M. Arnold who is said to have made the initial steps toward the cognitive approach. Assuming that not every perception leads to emotional reaction, she holds that there has to be some mechanism for evaluation of the situation, for judgement of the perceived stimuli regarding them either good, beneficial or bad, harmful for the organism's survival. The fact that the process of evaluation, appraisal develops in the rational mind comes to prove that cognitive elements also take part in the process of emotional experience (Arnold 1960). Thus, by introducing the element of appraisal in the overall pattern of the emotional state, the notion of emotion was enlarged and comprised the following sequential stages of evolvement:

1. Perception - the neutral reception of external stimuli;

2. Appraisal - a judgement of the stimuli as good and beneficial or bad and harmful; 
3. Emotion - a felt tendency towards stimuli judged as good and away from those judged as bad;

4. Expression - a pattern of physiological changes organized towards approach or withdrawal, differing for each emotion, which accompanies the felt tendency;

5. Action - approach or withdrawal may occur if another emotion does not interfere (Murray 1964:50).

Current research work on emotions is largely based on the findings of Cognitive Psychology and Philosophy (philosophy of emotions) which can be labeled in terms of the so- called affective neuroscience (Damasio 1994; Clore, Ortony 2000; Griffiths 1997; Goldie 2000). The focal point in this trend of research is the assessment of the cognitive element in emotional states. Research work in this field is aimed at defining to what extent the elements of the mental world - emotion and cognition are intertwined and interrelated. In this connection two theories of emotions can be distinguished: the somatic theory and the cognitive theory.

The somatic theory of emotions is based on W. James' ideas who treated emotions as feelings with some somatic sensations. This theory works within biological framework and treats emotions as physical or somatic phenomena, body states which are contrary to the psychological states of the soul. One of the proponents of the somatic theory of emotions is A. Damasio (1994) who holds that any mental image acquires a value of desirability which is a somatic marker and shows the body state. By using a body model and images with predicted future states of the body, he tried to find relations between mental images and the desirability of the body state. Thus, we may conclude that according to the somatic theory, our mind is physically associated with our body through brain.

It is also noteworthy that A. Damasio acknowledges two basic categories of emotions: primary and secondary. Primary emotions which are innate should be related to self-preserving and reproduction. Their triggering occurs on the subconscious level, when perceptive images excite them and cause a reaction that affects the actual body state. Meanwhile, secondary emotions which are experienced in everyday life can work both on the conscious and subconscious levels. A. Damasio explains that this phenomenon happens because of the fact that secondary emotions evolve from the primary ones and make use of the mechanisms of the former, but the conscious part of secondary emotions begins to work when they are triggered by some stimulus generated by a rational and conscious thinking. In this way, emotions are believed to be able to change the body's internal state and, consequently, affect the way the brain processes mental images (Damasio 1999).

According to the cognitive theory of emotions, which is propounded by some philosophers (de Sousa 1987; Solomon 1980 et al.), emotions always contain judgement which is either propositional, that is, articulated, conscious, or non-propositional - nonarticulated, subconscious. Thus, this theory holds that emotions consist in judgements and, naturally, admits the occurrence of the latter both on the conscious and subconscious levels. This theory also holds that there are certain innate emotions like fear, disgust, joy, etc. which can also occur on the subconscious level.

The findings of affective neuroscience as well as Cognitive Psychology and philosophy of emotions are important for us to understand the linguistic mechanism of explica- 
ture of emotions through verbal tokens. Thus, our brief theoretical survey enables us to conclude that a person's emotions (both conscious and subconscious) are evaluated (that is, assessed, judged) as positive and negative and become part of his/her background knowledge stored in the rational brain. As a result, any information which is able to be processed in the brain evokes certain emotions which may, accordingly, have a great impact on one's behaviour. Consequently, in certain cases one's verbal behaviour depends on the evaluation made on the spot, due to certain parameters of the communicative situation. Furthermore, sometimes emotions can be guided by rational mind due to background knowledge - cultural, ethnic, social, historical information stored in one's memory. Moreover, when making judgements on situations, evaluating events and individuals surrounding them, human beings are often guided by previous experience. Therefore, it should be stressed that a person's previous emotional experience can also determine his/her present emotional state and, accordingly, become verbalized in the process of communication.

In tune with modern theorists of emotions (cf. Ortony, Clore, Collins, LeDoux, et alias), we regard emotions essentially as subconscious signals and evaluations that inform, modify and receive feedback from higher cognitive processes. In a sense, we have to admit that human beings have two minds which are closely interrelated - emotional and cognitive. We should also admit that cognitive intelligence cannot work at its best potential without emotional intelligence.

The fact that every emotion is an experience involving a cognitive element, not merely a state of feeling, can be proved by quoting McTaggart: "We must hold that the cognition of that to which the emotion is directed, and the emotion towards it, are the same mental state, which has both the quality of being a cogitation of it, and the quality of being an emotion directed toward it" (McTaggart 1927:146).

This reasoning enables us to put aside the old opposition between raison d'etre and feeling (i.e. emotion vs. cognition) and try to find a sensible balance between the two minds. Admittedly, the paradigm where reason is seen completely unchained from emotions does not hold true, and a new one should be adopted, in which head and heart, feeling and thought, emotion and cognition are in harmony. The interrelation between emotion and cognition can be seen in Chart 1 presented below:

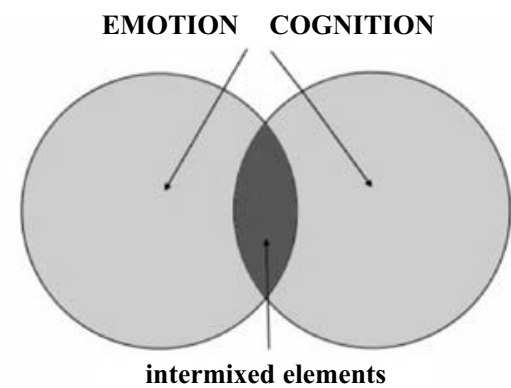

Chart 1: The Interrelation of Emotion and Cognition 
It is noteworthy that under certain circumstances the balance between cognitive and emotive minds gets lost: emotions come to prevail and, as a result, one loses the ability to properly estimate the situation at hand. Truly, in the heat of emotional obsession the ability to regulate his/her thoughts, behaviour and speech can be extremely diminished and in these situations one should take pains not to let emotions govern the cognitive part of the brain: once we lose the balance, we are sure to make wrong decisions and wrongly evaluate diverse situations. Consequently, we may even misinterpret different messages from the external world and respond to them inappropriately. This is the reason why when we are emotionally upset or anxious about something, we often state that we just can't think straight. The fact of being emotionally distressed can even hinder one's ability to learn and work properly and effectively. Sometimes, the influence of the emotions (positive or negative) is so enormous that the emotional mind becomes prevailing and one does not manage to control it. This fact actually finds its verbal and/or non-verbal manifestation - we say things for which we may later regret. Consequently, it is advisable that the balance should be kept in order not to be exposed to bewildering and misleading situations and subsequent misinterpretations. A good and sensible piece of advice which, unfortunately, is often so difficult for many of us to follow!

The following example comes to prove that emotional intelligence - the stored background knowledge of the interlocutors and their former negative disposition towards each other may greatly influence cognitive judgement in the process of communication. The spouses in the following stretch of talk are involved in conflict talk because the husband is inclined to contradict and argue:

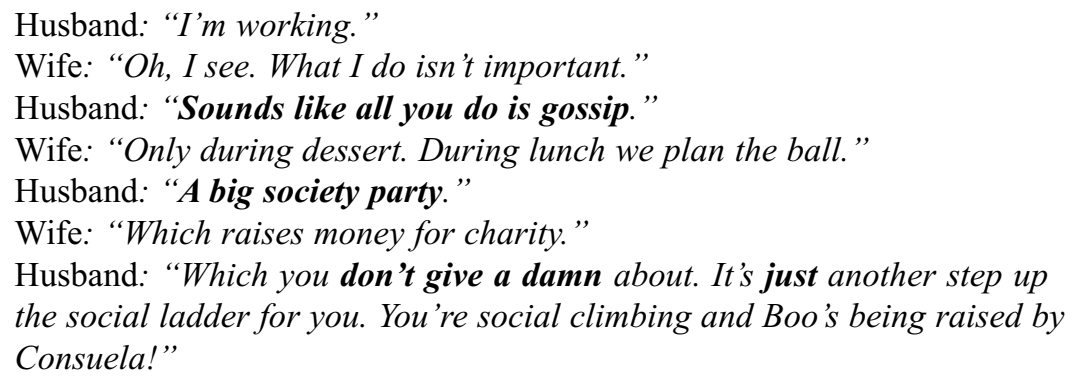

(M. Gimenez 2007:67)

In order to interpret the interrelation between emotive and cognitive aspects of speech adequately, it is necessary to turn to the context of situation. What lies at the root of the problem is the fact that the husband is dissatisfied with the behaviour of his wife and perceives it as irrational and inconsiderate. The spouses have drifted apart both physically and psychologically and the wife does not care about her family any longer:

But somewhere along the way - when, he wasn't sure - the heat had faded. And now they slept back to back, separated by two feet of king-sized mattress like a demilitarized zone.

(M. Gimenez 2007:66) 
The husband's negative emotional mind finds its actual expression through verbalization in the given context. It is being realized with the help of indirect speech acts of reproach/condemnation and cases of negative intensification.

The initial emotion which is displayed in the husband's speech is irritation, annoyance. This negative emotion is caused by his cognitive judgement: he thinks that his wife spends most of her time gossiping, which is bad. As we can see, the emotion spurring stimulus that is perceived by the husband in the negative light is not in the actual context but is a result of previous behaviour: having processed certain information cognitively, the speaker has evaluated it as negative and stored in his mental world. At the moment of speech the cognitive intelligence influences the choice of actual words and results in the expression of negative attitude towards the interlocutor which is expressed through indirect acts of reproach: Sounds like all you do is gossip; A big society party. By criticizing his wife, the husband intends to urge her to be more attentive towards her responsibilities. Contrary to this, the wife does not oppose overtly and does not impart negative feelings. She just tries to justify herself by proving the social significance of her work: after all she raises money for charity. As a matter of fact, the wife refuses implicitly to change her lifestyle, which adds to the husband's annoyance. He goes on condemning his wife's unreasonable behaviour who has left the upbringing of their child to the housemaid. Thus, the actual negative emotions - anger, irritation, discontent, disappointment - find their verbalization via the negative intensifier damn in the expression not to give a damn, and the particle just. As we can see, the realization of judgement-making about the external state of affairs occurs on the conscious level and can be considered as cognitive judgement; yet, its actual formation comprises both emotional and cognitive elements. No doubt the negative evaluation of the wife has been stored in the husband's emotional mind and outbursts in the given context in the form of negative speech units (reproach, condemning, negative denotational and connotational meaning), resulting in conflict talk.

Our analysis comes to prove that the prior positive or negative disposition of the interlocutors may change in the process of interaction depending on diverse extralinguistic factors. For instance, the tense relations experienced by two people every time they meet each other - such negative emotions as anger, annoyance, discomfort, contempt or irritation, may change in the positive direction, or just vice versa, previous positive emotional disposition may become negative. Let us analyze an example illustrating a spontaneous change of emotional mind in the process of interaction:

"I wanted to do this personally, Scott, so I could explain."

"She filed for divorce?"

Harry nodded. "Trey, the pro, he hired me - or he's paying me. He's

already won a tournament, a million bucks, so he can afford me."

Scott almost laughed. "We played golf how many times, Harry? A hun-

dred? And you're taking the money from the guy my wife ran off with?"

(M. Gimenez 2007:458) 
In this example the speakers have been good friends for quite a long time and experience positive emotions towards each other. Yet Harry, who is a lawyer, has accepted to undertake the divorce case of his friend's wife for money. When Scott learns about this, he feels depressed because he regards this act as treachery. So, his feelings towards his close friend change and Scott, undoubtedly, begins to experience rather negative emotions such as disappointment, annoyance, anger. Thus, the cognitive evaluation in the actual speech situation is negative: Scott has been betrayed by one of his best friends. The description of the author also implies this: Scott almost laughed. As we know emotions can be expressed both verbally and non-verbally. In this case the act of laughing does not denote the experience of such positive emotions as happiness, joy, delight; instead, it denotes the existence of negative emotions such as sadness, despair, disappointment. The approximator almost also shows that it was only a sarcastic laugh the illocutionary force of which was to condemn Harry. Thus, Scott scolds his friend indirectly, by issuing an act of reproach in the form of a question: We played golf how many times, Harry? A hundred? And you're taking the money from the guy my wife ran off with? The speaker's negative emotions are also manifested in his word choice: he achieves intensification of the negative effect by appealing to his interlocutor personally (Harry), as well as by using the numeral hundred in an elliptical utterance: the speaker experiences a change of emotional mind due to negative evaluation of certain parameters of the communicative situation. This change is expressed in his word choice and results in conflict talk.

In conclusion, one of the key claims of the present paper is the admission of the fact that emotions work on the cognitive background in the process of verbal interaction. Actually, they include both perception and appraisal functions and are closely related to higher cognitive judgement processes. We firmly believe that the emotional and cognitive minds are interdependent since they influence and regulate one another, with emotions stirring up and the rational mind analyzing, refining and sometimes vetoing or endorsing certain emotions.

\section{References:}

1. Arnold, M.B. (1960) Emotion and personality. Volume I: Psychological Aspects. New York: Columbia University Press.

2. Clore, G.; Ortony, A. (2000) Cognition in Emotion: Always, Sometimes, or Never? // Cognitive Neuroscience of Emotion. / Ed. by R.Lane and L.Nadel. New York: Oxford University Press.

3. Damasio, A. (1994) Descartes 'Error: Emotion, Reason, and the Human Brain. New York: G.P. Putnam's Sons.

4. Damasio, A. (1999) The Feeling of what Happens: Body and Emotion in the Making of Consciousness. New York: Harcourt Brace and Co.

5. De Sousa, R. (1987) The Rationality of Emotion. Cambridge MA: MIT Press.

6. Goldie, P. (2000) The Emotions: A Philosophical Exploration. New York, Oxford: Oxford University Press. 
7. Griffiths, P.E. (1997) What Emotions Really Are. London, Chicago: Chicago University Press.

8. Heritage, J. (2005) Cognition in Discourse. // Conversation and Cognition. / Ed. by H.te Moulder et al. Cambridge: Cambridge University Press.

9. James, W. (1890) Classics in the History of Psychology. // An internet resource developed by Christopher D. Green of York University. Toronto, Ontario. $<$ http://psychclassics.yorku.ca/James/Principles/>

10. Kasevich, B.V. (1989) Yazikovie structuri i kognitivnaya deyatel'nost'.// P.M.Frumkina (Ed.). Moskva: In-m yazikoznaniya AN SSSR.

11. McTaggart, J. (1927) The Nature of Existence. II. Cambridge: Cambridge University Press.

12. Murray, E.J. (1964) Motivation and Emotion. New Jersey: Prentice-Hall, Inc.

13. Oxford Advanced Learner's Dictionary (1997) Oxford: Oxford University Press.

14. Paronyan Sh., Bekaryan L. (2007) Mijandznya hakamartutyan khoskayin drsevorumnery jamanakakits anglerenum. // Otar lezunery bardzraguyn dprotsum, $\mathrm{N} 8$, Yerevan: EPH hratarakchutyun.

15. Paronyan, Sh. (2009) Discoursy vorpes giteliki kodavorman hamakarg. // Banber Yerevani hamalsarani, N 3/129. Yerevan: EPH hratarakchutyun.

16. Sanders, R.E. (2005) Validating "Observations" in Discourse studies: a Methodological Reason for Attention to Cognition. // Conversation and Cognition. Ed. by H. te Moulder et al. Cambridge: Cambridge University Press.

17. Solomon, R. (1980) Emotions and Choice. // Explaining Emotions. / Ed. by Amélie Rorty. Los Angeles: University of California Press.

18. Verschueren, S. (1999) Understanding Pragmatics. Amsterdam: Arnold Press.

\section{Source of data:}

1. Gimenez, M. (2007) The Colour of Law. London: Sphere.

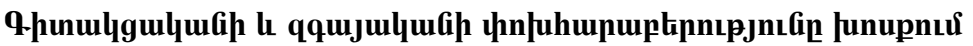

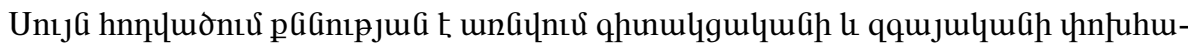
nuptinnıpjntip uimpnnt Gitpuz

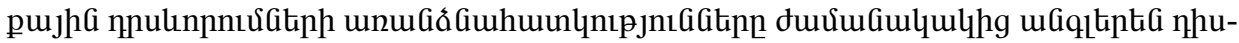

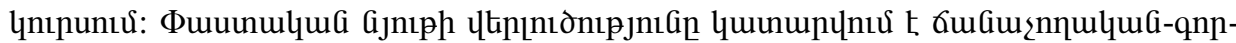

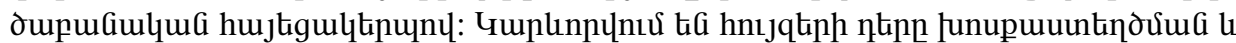

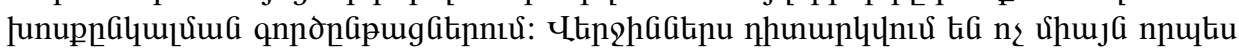

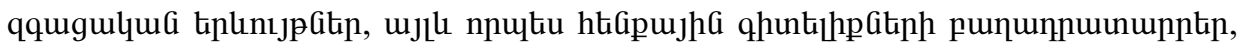

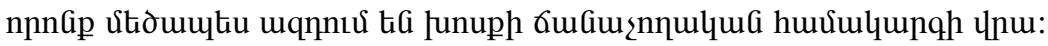

